DOI: 10.20472/IAC.2018.041.001

\author{
LEAH ACHDUT \\ The Ruppin academic Center, Israel
}

\title{
INCOME-WEALTH POVERTY: ISRAEL IN AN INTERNATIONAL PERSPECTIVE
}

\begin{abstract}
:
Over the last decade, attention has been drawn to a joint income-wealth perspective on living standards. Wealth affects living standards in more diverse ways than current income: it not only may generate direct flows of income, but also may enable families to smooth out consumption by relying on savings, assets and loans and protect them in times of economic distress. The purpose of this paper is to examine income-wealth poverty trends during the decade $2005-2015$ among Israeli aged 50 and older, compared to those in European countries. The study applies two approaches for integrating income and wealth: The first approach integrates income and wealth into one single dimension by converting wealth into annuity, while the second approach applies a two-dimensional framework and specifies poverty threshold for each dimension separately. Wealth poverty, called also financial distress, is seen as a situation where asset holdings are insufficient to maintain the household at a minimally acceptable living standard for a given period.
\end{abstract}

The study is based on data from SHARE-Israel, conducted as part of the SHARE project (Survey of Health, Aging and Retirement in Europe). SHARE is longitudinal survey on people aged 50 and older, and it includes detailed information on disposable income and on the value of the various components of real assets, financial assets and debts. We found that (a) the traditional income poverty rate was relatively stable and ranged from $21 \%$ to $24 \%$. (b) poverty rates according to the unidimensional approach were quite similar to the traditional income poverty rates.(c) the proportion of families in financial distress was much lower: between $8.2 \%$ and $10.0 \%$. In other words, the net wealth of about $8.2 \%-10.0 \%$ of all families was insufficient to maintain the household at the income poverty line for 3 months. Moreover, about $7 \%$ of the families had wealth less than three times of their current monthly income. (d) compared to European countries, Israel is located in the top third of the traditional income poverty scale, but in the bottom third of the financial distress scale.

\section{Keywords:}

Poverty, wealth, income, SHARE, Israel

JEL Classification: D31 